\title{
Identification of biofilm composition covering lime-based materials
}

\author{
Klára Kobetičová ${ }^{1}$, Jana Nábělková, $^{2,}$, and Václav Kočí ${ }^{1}$ \\ ${ }^{1}$ Department of Materials Engineering and Chemistry, Faculty of Civil Engineering, Czech Technical \\ University in Prague, Thákurova 7/2077, 16629 Prague 6, Czech Republic \\ ${ }^{2}$ Department of Sanitary and Ecological Engineering, Faculty of Civil Engineering, Czech Technical \\ University in Prague, Thákurova 7/2077, 16629 Prague 6, Czech Republic
}

\begin{abstract}
This paper aims at identification of biofilms composition taken from lime and lime-cement plasters. The samples of plasters were exposed to natural weathering for more than three years to weather conditions of Prague as a representative of Central European continental climate. After biofilms sampling, they were cultivated using specific nutrient solutions and analysed using various types of microscopes. It was found, that the plasters were covered mostly by green algae (Hematococcus pluvialis, Klebsormidium sp., Trebouxiophyceae, Chlorophyceae and Chlorellaceae), cyanobacteria (Nostoc, Anabaena, Leptolyngbya, Phormidium, Plectonema, Synechococcales and Oscillatoriale), moulds (Aspergillus niger, Alternaria) and moss (Ceratodon purpureus). Possible influence of these organisms on hygrothermal behaviour of the base materials is subsequently discussed.
\end{abstract}

\section{Introduction}

Biodegradation is an undesirable process that can affect not only the aesthetical, but also physical and chemical properties of building materials. While the aesthetical biodegradation can negatively affect only the building materials' appearance, the chemical can cause for instance degradation of concrete due to the emanation of metabolites of microorganisms. The physical biodegradation includes all activities leading to physical damage of building materials. The rate of damage is correlated not only with the type and size of microorganism, type of material, environmental conditions, microclimatic exposure, but also with the level and type of air pollutant [1].

In most cases, the biodegradation is caused by biofilms that may cover material surfaces. The composition of biofilms differs depending on the various environmental or material actors [2]. However they usually contain bacteria, fungi, algae, lichen and moss. The algae and cyanobacteria can be considered as pioneering inhabitants on surface of building materials. They need just $\mathrm{CO}_{2}, \mathrm{~N}_{2}$ and salt minerals traces [1]. Their main role in degradation consists in their ability to etch mineral components [3], increase microcracks [4] or form coloured patinas [5].

* Corresponding author: nabelkova@fsv.cvut.cz 
Being presented within this paper, identification of biofilms composition is a key factor to reveal their potential impacts. The analysis represents an initial step towards deeper understanding of biological actions that may affect a hygrothermal performance of building facades materials.

\section{Materials and methods}

Selected samples of lime and lime-cement plasters were taken from a test site where they had been exposed to long term weathering within a previous research project. Beside weather effects observed on the samples' structure, also green biofilms were detected on the samples' surface. These biofilms were subsequently subjected to a qualitative analysis of their composition.

In order to cultivate different groups of organisms (algae, cyanobacteria), the samples were soaked into specific solutions of nutrients: BBM and BG11 medium from CCALA (Czech Academy of Sciences, Czech Republic) for algae and cyanobacteria, maltose agar from P-Lab, Ltd. (Czech Republic) for moulds. A part of the samples was also used for a direct imprint method for moulds cultivation using Petri dishes, having a diameter of $9 \mathrm{~cm}$, with $3 \%$ nutrient agar. The cultivation of organisms was carried out under controlled temperature $\left(22 \pm 2{ }^{\circ} \mathrm{C}\right)$ and illumination $(16 \mathrm{~h} / 8 \mathrm{~h}$, light/dark $)$ in a biological thermostat. It took two months in case of algae and cyanobacteria and two weeks in case of moulds. The sampling of mosses was done by means of pouring in medium for non-seed plants (CCALA, Czech Academy of Sciences, Czech Republic) for one week, allowing a better recognition of a frond division.

After finishing of the cultivation procedures, a determination of organisms was done using a light microscope (Olympus) equipped with a digital camera system. The organisms were determined into family, genus or species. Unlike microorganisms, the moss was determined under a stereo microscope (Olympus).

\section{Results and discussion}

\subsection{Algae}

The most abundant alga was species Hematococcus pluvialis (see Fig. 1a), which is reported as very common and widely distributed species in Europe. H. pluvialis is usually found on sandstone, granite, marble, limestone [6] and it was also recognized in urns or shallow pools formed in rock hollows which are either periodically filled with rain or supplied by water oozing from overhanging ledges [7]. H. pluvialis can produce astaxanthin [8] as an antioxidant under stress conditions. This species belongs to the first colonisers of materials and its growth rate can be negatively correlated with the abundance and species richness of the other autotrophs [9]. 


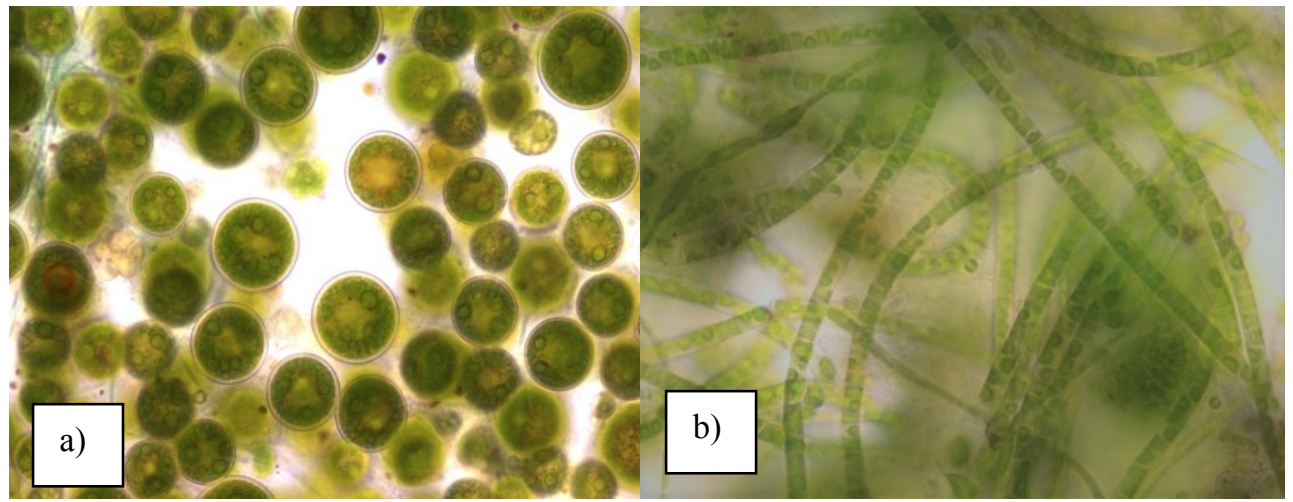

Fig. 1. Algal species a) Hematococcus pluvialis, b) Klebsormidium sp.

Klebsormidium sp. (see Fig. 1b) was described as a representative of filamentous algae. This terrestrial species has been often found on sandstones as well as limestones [10]. According to literature, Klebsormidium strains isolated from limestones showed the highest growth rates at $\mathrm{pH}$ levels from 7 to 8 . Generally, strains of Klebsormidium show a wide range of adaptation to unfavourable conditions [10] or presence of heavy metals [11]. The other green algae found in the studied samples were from Trebouxiophyceae, Chlorophyceae and Chlorellaceae families.

\subsection{Cyanobacteria (blue-green algae)}

In the present study, genus Nostoc (see Fig. 2a), genus Anabaena (see Fig. 2b) and mixture of thin various filamentous cyanobacteria belonging to the artificial working group including cyanobacteria as Leptolyngbya, Phormidium, Plectonema, Synechococcales and Oscillatoriale were determined on the studied samples.

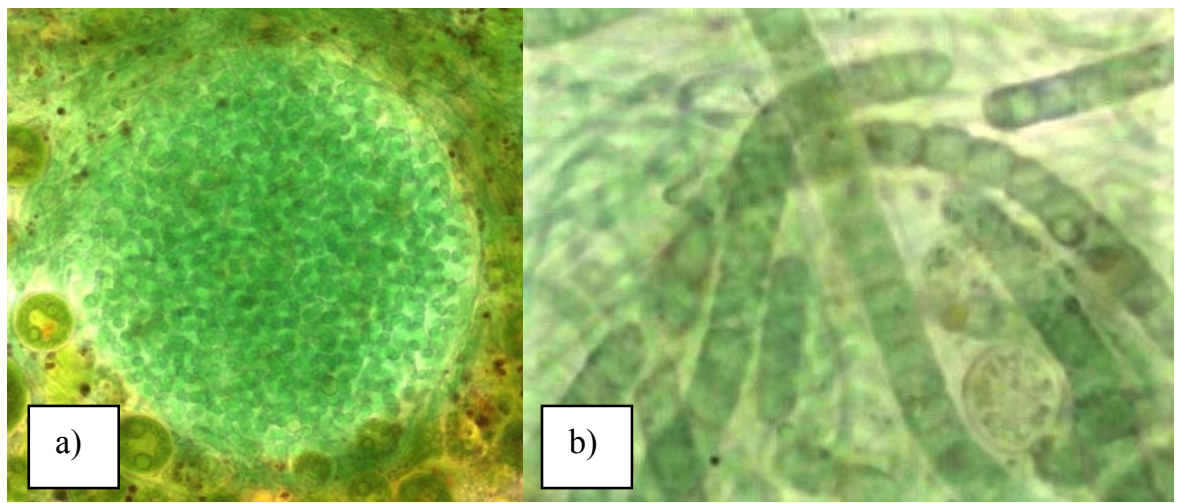

Fig. 2. a) Cyanobacteria of genus a) Nostoc, b) Anabaena.

According to findings presented in the literature, it was observed that aerial and terrestrial cyanobacteria tend to prefer more alkaline environments and their development could be significantly limited on low $\mathrm{pH}$ substrates [12]. It is in accordance with findings observed within this study, because $\mathrm{pH}$ of eluates from the studied samples (100 $\mathrm{g}$ of dried sample per $1 \mathrm{~L}$ of distilled water) was between 7 and 9 . 


\subsection{Moulds}

Moulds of species Aspergillus niger (see Fig. 3) and genera Alternaria were recognised on agar plates after imprinting of plasters. Both the genus, Aspergillus and Alternaria, are quite common in environment as well as in interior of houses. They are sources of spores that can cause allergic reaction or asthma to sensitive people [13]. According to the results presented by Luo et al. [14], due to dissolving of $\mathrm{Ca}(\mathrm{OH})_{2}$ from cement materials by moulds, the $\mathrm{pH}$ of the growth medium can increase from the original value of 6.5 up to 13.0. It is possible that moulds as the algae and bacteria (they were not studied in the present study but their presence can be expected) were participating on calcium solution in lime building materials.

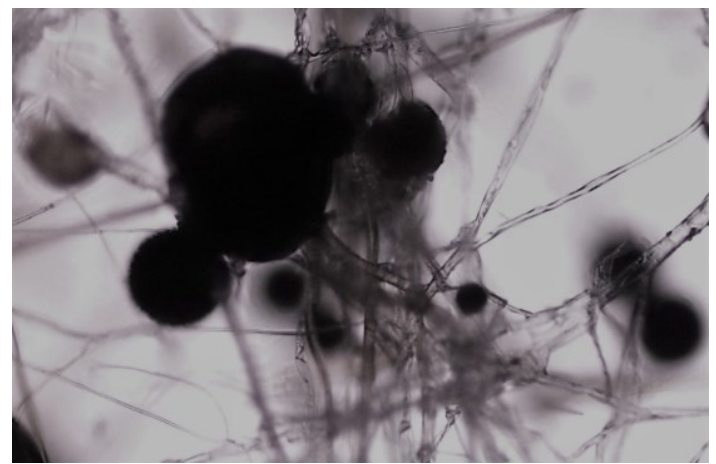

Fig. 3. Mould species Aspergillus niger - conidiophores (black globules) and hyphae.

\subsection{Moss}

Species Ceratodon purpureus (see Fig. 4) was determined according to the atlas of mosses [15]. This species is a widespread, weedy, short moss forming dense tufts or pads. It occurs on all types of substrates - gravel and sand, wood, rocks, but also on old roofs and cracks in pavements. It tolerates a wide range of $\mathrm{pH}$ values and a much higher level of pollution than other mosses [15]. This organism, unlike microorganisms, was found only on highly disturbed materials.

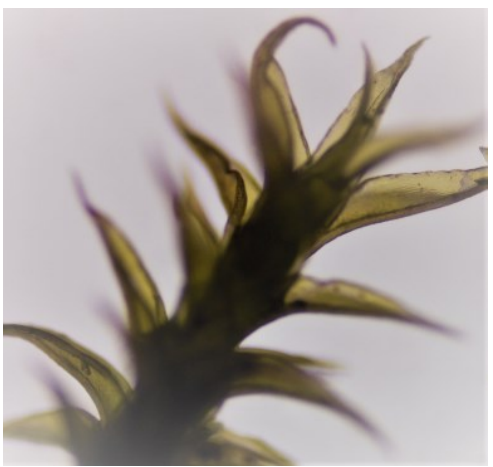

Fig. 4. Moss species Ceratodon purpureus. 


\section{Conclusions and future work}

Identification of biofilm composition under Central European climate was done within this research. For this purpose, selected lime-based plasters were exposed to natural weathering for several years. Spherical and filamentous algae, cyanobacteria, moulds and one species of moss were recognised on the studied samples. Since the systematic determination into species is beyond possibilities of department as it requires methods of molecular biology, it was not performed at all, except some evident species. Furthermore, it is not necessary regarding to the long-term objectives of the project this research was carried out within.

All of the organisms determined appeared to be cosmopolitan with simple nutrition and humidity requirements and wide ecological tolerance. Their occurrence on the samples after 3 years of natural weathering can be ascribed to a complicated mutual biological interaction and supply of nutrient from biodegradable building materials. It is supposed that presence of biofilms on surface of plasters might affect the hygrothermal performance of theirs as it might (i) contribute to increase of relative humidity of the substrates thanks to exclusion of metabolites, (ii) create a protective layer and affect an income of liquid water, (iii) amount of absorbed sun radiation, (iv) water vapor diffusion or (v) heat transfer through the substrate.

The future research will therefore focus on effect of biofilms on changes of heat and moisture transport and storage properties of the substrates involved as well as on precise determination of hygrothermal patterns for the optimal biofilms growth rate.

This research has been supported by the Czech Science Foundation under Project No 19-01558S. The authors would also like to thank to Dr. Alena Lukešová from the Biology Centre of the Czech Academy of Sciences for her consultations regarding to algae determination.

\section{References}

1. P. Tiano, Biodegradation of cultural heritage: decay, mechanisms and control methods (New University of Lisabon, Portugal, 2002)

2. C.C. Gaylarde, P.M. Gaylarde, Int. Bioter. Biodegr. 55, 131 (2005)

3. A. Danin, R. Gerson, K. Marton, J. Garty, Palaeogeogr. Palaeocl. 37, 221 (1982)

4. C.C. Gaylarde, M.R. Silva, T. Warscheid, Mater. Struct. 36, 342 (2003)

5. A. Dubosc, G. Escadeillas, P.J. Blanc, Cement Concrete Res. 311613 (2001)

6. P. Doddy, C.M. Roden, Biol. Environ. - Proceedings of the Royal Irish Academy 114B, 71, 2014.

7. T.E. Hasen, Memoirs of the Torrey Botanical Club 6, 211 (2019)

8. K. Saini, Y.S. Keum, Food Chem. 240, 90 (2018)

9. S. Genitsaris, N. Stefanidou, M. Katsiapi, E. Vardaka, K.Ar. Kormas, U. Sommer, M. Moustaka-Gouni, Turk. J. Bot. 40, 427 (2016)

10. D. Ryšánek, A. Holzinger, P. Škaloud, Phycol. 55, 347 (2016)

11. L.A. Gaysina, E.S. Purina, L.M. Safullana, G.R. Bakieva, Plant Sci. 3, 39 (2009)

12. T. Smith, T. Piccin, Southwest. Nat. 49, 395 (2004)

13. C.M. Er, N.M. Sunar, A.M. Leman, N. Othman, Methods X, 340 (2015)

14. J. Luo, X. Chen, J. Crump, H. Zhou, D.G. Davies, G. Zhou, N. Zhang, C.R. Jin, Constr. Build. Mater. 164, 275 (2018)

15. B.P. Kramer, Lišejníky, mechorosty, kaprad’orosty (Ikar, Czech Republic, 1998) 